\title{
A RELAÇÃO ENTRE ESTADO, TRABALHO, CAPITAL E OS SENTIDOS DAS POLÍTICAS EDUCACIONAIS NO BRASIL
}

Leonardo Dorneles Gonçalves ${ }^{1}$

\section{RESUMO}

O presente trabalho aborda a relação entre Estado, Capital e Trabalho na configuração das políticas educacionais no Brasil, principalmente a partir da década de 1990. Com objetivo de compreender a atualidade das políticas educacionais, elencamos as principais alterações ocorridas no plano educacional, contando com os estudos de Leher (2009, 2014), Shiroma et al. $(2002,2014)$ entre outros, os quais têm pesquisado as políticas educacionais na perspectiva da luta de classes em curso no país. O estudo demonstra que as transformações do papel do Estado têm direcionado as políticas educacionais para atender às necessidades da formação de uma força de trabalho útil aos mecanismos de exploração que o capitalismo impõe a países periféricos, como é o caso do Brasil. Por isso, a educação e a escola pública sofrem transformações de ordem administrativas/gestão e pedagógicas.

Palavras-chave: Políticas educacionais. Capital. Trabalho.

\begin{abstract}
This paper explores the idea of how State, Capital and Labor had a role in the directions of Brazilian educational policies. This article tried to discuss how the current educational policies have been changing since the nineties. For this was used Leher, Shiroma and authors who work with educational policies according the class struggle perspective. This article came as a result from a doctoral research that made an analyze of High School's curriculum changes in RS. Concluding, the changes occurred into the labour world provokes an redefining into the State role; also, its directs the educational policies to attend the demands of a formation for passive labor force. Those are the reasons that public education are undergoing management and pedagogical changes.
\end{abstract}

Keywords: Educational policies. Capital. Labor.

\footnotetext{
${ }^{1}$ Doutor em Educação (UFPel). Membro do Grupo de Pesquisa MOVSE - Educação, Movimentos Sociais e Escola Pública - UFPel
} 


\section{INTRODUÇÃO}

A atualidade das políticas educacionais brasileiras tem demonstrado a frágil relação institucional construída até hoje, a fim de garantir, efetivamente, a educação como um direito. Os limites podem ser evidenciados nas modificações legais que afetam a educação pública, sobretudo aquelas que enfocam a limitação dos recursos financeiros destinados ao custeio do ensino público, bem como as alterações curriculares - como temos acompanhado em relação ao ensino médio -, as quais objetivam um ajuste da formação aos interesses do mercado e a transformação da própria educação em mercadoria.

Entretanto, quando olhamos o caso das políticas públicas educacionais no Brasil, as determinações fundamentais para ocorrência desses retrocessos encontram-se em dois movimentos distintos e relacionados. O primeiro diz respeito à natureza e formação social brasileira e aos direitos sociais aqui instituídos, que são atravessados por uma relação assimétrica e promíscua entre os interesses privados e públicos, a qual pode ser mais bem compreendida pelo sentido patrimonialista da constituição de nossa sociedade. O segundo movimento sugere que olhemos com atenção para as ações das classes dominantes e para as formas por elas criadas para controlar as políticas educacionais, principalmente a partir dos anos 1990.

Portanto, o texto que segue apresenta, principalmente, uma análise da relação entre Estado, Capital e Trabalho, buscando elucidar como tal relação permite que as classes dominantes reorientem suas formas de controle sobre as políticas públicas educacionais. Essa reorientação é marcada pela substituição de um modo menos eficaz de controle, caracterizado pelas ações das parcerias público-privadas, pelo direcionamento do fundo público e sentido administrativo e pedagógico das políticas transcorridas a partir de mecanismos internos do Estado, o que ocorre, principalmente, após o início dos anos 2000.

Ao caracterizar este processo de reorientação dos rumos das políticas educacionais, enfatizando seus desdobramentos a partir das formas de organização da gestão educacional, mudanças curriculares e responsabilidades apresentadas às instituições de ensino, entende-se que o sentido das políticas educacionais e a sua lógica de funcionamento expressam a relação entre Estado, Capital e Trabalho sob as condições da formação social brasileira, ainda que a 
forma de atuação das políticas seja distinta para atender às necessidades de consentimento de uma classe sobre a outra.

\section{Políticas educacionais: mudanças e novos rumos}

Formalmente, o transcorrer das políticas educacionais no Brasil dá-se a partir de um percurso que, por um lado, pode ser entendido como contraditório e, por outro, como manifestação das conquistas dos grupos socialmente organizados pela garantia de direitos. Tal compreensão nos levaria ao limite de entender as políticas educacionais como a expressão de conquistas e concessões, simultaneamente, de acordo com os interesses em disputa. Mas, parece-nos que os elementos que giram em torno das políticas são mais complexos e correspondem a uma estratégia que visa solucionar a crise do Capital e construir um consenso em torno do modo de produção capitalista.

$\mathrm{Na}$ esteira de Leher (2014), entende-se que a atualidade da política educacional brasileira, ou o seu desenvolvimento atual, deve ser compreendida através da dinâmica de um processo histórico com retrocessos e avanços, mediatizados pela, até então, insuperável lógica de acumulação capitalista e por sua influência na direção do desenvolvimento e, por conseguinte, das políticas. Em geral, isso significa que, dependendo da correlação de forças existente na base da sociedade, os nexos entre as políticas educativas e o padrão de acumulação capitalista aproximam-se e/ou distanciam-se, assumindo formas históricas diversificadas. Segundo o autor, o principal interesse dos setores dominantes nas políticas educacionais é melhorar a "qualidade do trabalhador" (p. 163), para que seja um elemento importante no círculo da produtividade. A sustentação teórica dessa afirmativa encontra-se na Teoria do Capital Humano, a qual estabelece uma relação direta entre a elevação do nível escolar e a formação de força de trabalho com aumento da produtividade e dos excedentes.

No caso brasileiro, com base nas análises de Leher (2009, 2014), destacamos, resumidamente, três importantes momentos da recente história nos quais as políticas assumiram contornos específicos, sobretudo pelas características da correlação de forças em cada momento. O primeiro foi o período em que predominou a ditadura civil-militar e coincidiu com a ascensão das teses do capital humano, as quais foram deliberadamente assumidas nas políticas educacionais e traduzidas em orientações que modificaram a estrutura 
da educação brasileira, com o fim de colocar a formação escolar/universitária a serviço das orientações demandadas pela aceleração industrial ${ }^{2}$.

O segundo ocorreu com o processo que culminou na redemocratização do país e criação da nova constituição federal, quando houve, em certa medida, uma participação popular ampliada e massiva nos debates em torno do direcionamento que o país deveria assumir, ainda na sombra da ditadura. Naquele contexto, o tema da escola unitária e politécnica, somada às duras críticas à orientação pedagógica do capital humano, não chegou a incidir diretamente na política educacional, mas deixou um importante legado, inclusive a existência de fóruns de debates, associações de professores, sindicatos e outras organizações que até hoje são fundamentais para pensar os caminhos das políticas educativas do país.

O terceiro momento corresponde, segundo Leher (2014), à crise das lutas sociais e da própria teoria crítico-socialista, devido à ofensiva do capital, que se caracteriza por dois movimentos: 1) ligado à introdução das teorias do fim do trabalho e à emergência de temas contingentes, a partir das identidades de gênero, etnia, sem necessariamente uma orgânica articulação com a situação de classe; 2) o protagonismo e a retomada das teses do capital humano, sustentadas em documentos produzidos pelo Banco Mundial, nos quais se reafirmava a importância dessa teoria sobre qualquer outra no campo da educação. Esses dois movimentos, articulados, dão início a uma nova etapa das políticas educacionais brasileiras, marcada pela inserção lenta e gradual dos interesses dos empresários na orientação das políticas educacionais, sob a justificativa de que a escola pública fracassou na missão formativa.

A influência dos interesses do empresariado se apresenta com algumas características que foram analisadas por Carvalho (2009), Shiroma et al. (2002; 2014) e Peroni (2006; 2013), além de Leher (2014). Com base nos autores, é possível afirmar que a política educacional em curso no Brasil nas últimas décadas tem sofrido influência das forças empresariais, o que ocorre através de diferentes formas organizativas, a depender das estratégias adotadas para que a incorporação desses interesses na agenda educacional se efetive e, com isso, não haja resistências. Para nós, o movimento de ampliação de hegemonia que tem sido operado no âmbito da política educacional brasileira caracteriza-se como uma faceta, uma manifestação da crise do modo de produção capitalista, o qual passa a demandar do Estado (políticas) uma

\footnotetext{
${ }^{2}$ Leher (2014) lembra-nos dos acordos da "Aliança para o progresso" (1964), MEC-USAID (1967-1968) e a Lei $\mathrm{n}^{\circ} .5692 / 1971$ (LDB).
} 
atuação mais direta em seu favor. Tal movimento expressa-se como estratégias para que a educação/escola pública e os recursos que a ela são destinados sejam direcionados à (con)formação de uma força de trabalho disponível, inclusive, para ser sobrante ou hiperexplorada (ANTUNES, 2008).

Este movimento atende à necessidade que o Capital impõe ao Estado, no sentido de engendrar uma radical flexibilização da sua influência no campo da economia e na interferência de sua ação junto às políticas públicas, a partir de justificativas ideológicas como a ineficiência do Estado e sua burocratização. Por isso, desenvolve-se no Brasil, na década de 1990, a Reforma do $\mathrm{Estado}^{3}$, cuja ideia é realizar transformações no plano administrativo e da gestão, de modo que o funcionamento do Estado não obstaculize a ampliação do Capital, mas fortaleça-o nos marcos da reestruturação produtiva, conforme é analisado a seguir:

\begin{abstract}
Nessa reforma, na perspectiva de seus proponentes, o Estado deve responder com maior rapidez e eficiência às constantes mutações do mercado global e às demandas sociais, exercer um papel mais decisivo na reestruturação produtiva e diversificar as fontes de financiamento. Vê-se na reforma a possibilidade de se flexibilizar a ação estatal e de se liberar a economia, conduzindo-a a um novo ciclo de crescimento econômico e, ao mesmo tempo, proporcionar ao Estado maior governabilidade. Em face disso, o problema da eficácia administrativa torna-se questão central nos debates e nas reformas políticas dos anos de 1990, em meio aos quais o novo modelo de gestão pública que se apresenta é o gerencial. (CARVALHO 2009, p. 1145).
\end{abstract}

Levando em conta a análise de Carvalho (2009), as políticas educacionais brasileiras a partir da década de 1990, desde o processo de elaboração e tramitação da Lei de Diretrizes e Bases $n^{\circ}$ 9394/1996 até as interferências dos empresários - por meio de suas fundações - na educação pública, sofreram alterações que jamais foram revertidas. Ao contrário, de acordo com Shiroma (2002), a constituição do consenso em torno de um projeto de sociedade cuja base é a manutenção de relações sociais capitalistas determinou como a agenda educacional seria desenvolvida na garantia de que os interesses dos empresários tivessem respaldo nas políticas públicas educacionais ${ }^{4}$.

Decorre da caracterização acima apresentada por Carvalho (2009) a implantação de políticas educacionais que buscaram estabelecer uma relação aproximada entre as ações dos

\footnotetext{
${ }^{3}$ À época, foi constituído o Ministério de Administração e Reforma do Estado (MARE), que teve como ministro do Sr. Luiz Carlos Bresser Pereira.

${ }^{4}$ A saber: um ator protagonista neste contexto foi o Banco Mundial e o receituário apresentado aos países no campo da educação, prioritariamente a educação básica. Como parte da barganha para acessar o financiamento, o Banco determinava reformas administrativas que fossem condizentes com os pressupostos do mercado, o que encontrou interlocução interna dos países, como nos lembra Torres (1996).
} 
governos e o modelo empresarial. As denominadas "parcerias público-privadas" são o exemplo mais apropriado, uma vez que, neste contexto, a fim de diminuir as funções do Estado e delegá-las às organizações da sociedade civil e não governamentais (nada mais adequado para ser chamado de privatização), as políticas educacionais foram conduzidas pelas intervenções diretas de entidades e instituições beneficiadas pela transferência de recursos públicos ao setor privado. No contexto brasileiro, essa relação ficou conhecida como "terceira via", ou seja, a tentativa de transformar e transferir os direitos sociais para o setor de serviços.

Além disso, a introdução das ideias gerencialistas e da enganosa retórica que afirma que a necessidade de enxugamento do Estado perpassa pela diminuição de suas ações, idealizado como um Estado Regulador (e cada vez menos provedor), ofereceu elementos para que as políticas educacionais fossem absorvidas pela lógica representada pela máxima "fazer mais com menos". As implicações dessas mudanças influenciaram diretamente a elaboração da LDB nº 9394/1996, a qual incorporou uma série de dispositivos que permitiram a influência da "sociedade civil" nas atividades educacionais/escolares. Neste caso, o conceito de sociedade civil parte de uma condição irreal em que as diferentes posições de classe seriam subsumidas pela garantia do direito a educação. Na prática, são exatamente as contradições de classe que permitem que a educação pública, destinada em sua maioria aos filhos dos trabalhadores, seja controlada pela classe dominante.

A análise de Shiroma e Evangelista (2013) contribui para a caracterização deste modelo de Estado posto em prática no curso pós década de 1990:

Uma das estratégias desse modelo de gestão pública é a de aumentar a eficiência da
ação governamental por meio da descentralização de tarefas para esferas locais,
induzindo as parcerias e o fortalecimento das ideias de "empoderamento" e de
"protagonismo local". De outro lado, a suposta partilha de responsabilidades com
organizações da Sociedade Civil imputou-lhe o sentido de "Terceiro Setor",
constituindo-as como parceiras e corresponsáveis no provimento das políticas
sociais. No Brasil, esse expediente foi impulsionado pela Reforma do Estado dos
anos de 1990, ao definir que caberia ao Estado gerenciar os processos enquanto as
"organizações sociais" - sob a forma de fundações e institutos privados -
executariam as políticas sociais com recursos públicos. Esse breve percurso permite
compreender os fenômenos da multiplicação das parcerias público-privadas, a forte
inserção do setor privado na definiçãa e execução de políticas públicas, o aumento
da participação de empresários em conselhos sociais do governo federal. Conclui-se
que o Estado não se afastou para dar espaço ao setor privado; ao contrário mantém-
se presente, mas não como provedor exclusivo dos serviços públicos - entendidos
como atendimento ao público -, e sim como regulador. Modificou-se a configuração
do Estado, a participação de organizações da Sociedade Civil, em especial de
empresários, na formulação de políticas públicas, com repercussões sobre a 
reposição da hegemonia burguesa, problema central para governar. (SHIROMA; EVANGELISTA, 2013, p. 24).

Considerando a análise, o que mudou foi a direção e o desenvolvimento das políticas públicas educacionais a partir dos anos 1990, o que leva as autoras a rever o argumento e analisar o movimento da realidade de acordo com aquilo que, de fato, tem acontecido. Precisamente, sob orientação gerencialista, cuja base fomentou as parcerias público-privadas configurando o início da influência direta dos empresários no campo da educação, as políticas educacionais foram conduzidas pela "necessidade" de reformar o Estado e atender à pressão do Capital para direcionar o sentido das ações dos governos no setor. Essa foi uma realidade, principalmente, na segunda metade da década de 1990, a qual coexistiu com a ameaça forte de privatização da educação pública, principalmente do ensino técnico e superior.

O movimento que se expressa no início do século XXI e que caracteriza as políticas educacionais, nestas primeiras décadas, apresenta-se qualitativamente distinto daquelas parcerias público-privadas que inauguraram a reforma gerencial do Estado. O que se efetiva, para que os empresários radicalizem suas influências e o controle das orientações às políticas educacionais, parte da unidade entre as diferentes frações da classe dominante nacional, para que, deste âmbito dos espaços públicos, controlem as ações que devem acontecer em termos de educação. Segundo Leher (2014), o diagnóstico da classe dominante brasileira é que a educação pública não cumpriu com sua função, pois a escola não apresenta qualidade. Mesmo diante da ampliação do acesso a educação, falta qualidade na escola pública, o que deve ser traduzido na elevação dos índices de aprovação e diminuição dos índices de evasão escolar.

$\mathrm{O}$ autor explicita o início desse processo:

Em 2001, uma fração importante desses empresários criou um Movimento com o sugestivo nome de "Brasil Competitivo", liderado e organizado por um empresário cuja origem é no Rio Grande do Sul: Jorge Gerdau Johannpeter, do Grupo Gerdau. O que faz esse grupo? Começa a organizar setores empresariais para discutir a suposta falta de qualidade da educação pública. Eles difundem um diagnóstico que não é original, pois já está presente nos documentos de um movimento chamado Programa de Reforma Educativa na América Latina e Caribe - PREALC. Quem financia o PREALC é a Agência Estadunidense de Desenvolvimento -, a Fundação Ford, o Banco Mundial. Em suma, os grandes intelectuais coletivos do capital. Qual é o diagnóstico que eles fazem da falta de qualidade? Essencialmente eles estão dizendo o seguinte: os educadores fracassaram, a escola pública foi generalizada, mas é uma escola pública "sem qualidade". Quem sabe fazer as coisas acontecerem? A resposta é óbvia: os empresários. E estes não podem se omitir diante da falência da escola pública, pois isso poderia custar caro à competitividade do país (LEHER, 2014, p. 169). 
Assim, a influência do empresariado ${ }^{5}$ nas políticas educativas ganha força gradativamente e de forma silenciosa. A continuidade desse processo acarretou, em 2006, a criação do movimento "Todos pela Educação", formado pelas mesmas instituições. Enquanto organização que reúne uma fração poderosa da classe dominante, esse movimento exerce influência sobre os mecanismos de decisão que orientam a elaboração das políticas públicas educativas. Pode-se dizer que a sua atuação é, ao mesmo tempo, visível e invisível, uma vez que todos conhecem o seu poder desigual de persuasão e os meios que se utilizam para fazer valer os seus interesses, mas, no que tange ao caminho "legal" das políticas, as suas representações (políticas) assumem o seu papel e as suas consequências.

Além da intervenção dos interesses empresariais nas políticas, é característico desta relação que envolve as ações o incremento da lógica do mercado nas relações que constituem o todo do processo educativo, mobilizado pelas políticas públicas (a lógica das metas demonstra isso), inclusive nos instrumentos democráticos que contam com a participação do povo, como é o caso do Plano Nacional de Educação. Para Leher (2014), nunca vivemos tal situação na educação pública, pois "a cultura das metas, de bater metas, torna-se política de governo e, mais que isso, entra na lei para ser duradoura" (p. 174).

Contudo, é preciso demonstrar que a crise do Capital atinge o Estado e, por sua vez, reconfigura o funcionamento das políticas educacionais. O Estado não se tornou mínimo, mas incorporou mecanismos sofisticados que ampliaram o seu controle pelo empresariado no que diz respeito à direção a ser dada às políticas públicas educacionais. Estas, no primeiro momento realizadas por organizações e institutos ligados às grandes empresas, passam a ter características de mercado, pelo controle da gestão dos sistemas de ensino - via sistemas

\footnotetext{
${ }^{5}$ Leher (2014) nomina alguns grupos empresariais, Banco Itaú-Unibanco, Bradesco, Santander; os grandes meios de comunicação, Fundação Roberto Marinho, Victor Civita; corporações da indústria editorial; setores metalúrgicos, como a Vale e o próprio Grupo Gerdau; os representantes do agronegócio, como a Monsanto (p. 170).

${ }^{6}$ Esse movimento apresenta-se como organização da sociedade civil e funciona, basicamente, por meio da influência dos seus interesses particulares nas políticas públicas da educação, as quais têm sido generalizadas a toda a sociedade, com objetivo de constituir um consenso em torno de suas demandas. Concretamente, essa relação tornou-se cristalina a partir da criação do Plano de Desenvolvimento da Educação - PDE (2006-2007) pelo governo federal, cujo documento-base assume implementar as metas estabelecidas pelo "Movimento Compromisso Todos pela Educação", forjadas a partir dos índices de avaliação internos e externos que são adotados pelo governo. Isso se torna possível devido ao trânsito livre que os membros dessa organização têm entre as instituições do Estado (LEHER, 2014, p. 171-172). Outra forma encontrada pelo movimento para influenciar os caminhos das políticas educativas é por meio das Organizações da Sociedade Civil de Interesse Público (OSCIP), as quais são representantes dos empresários na relação direta através das políticas de Estado e dos governos.
} 
informatizados com base no alcance de metas -, pelo regime de colaboração ou pela organização escolar, ainda que o discurso em prol da participação democrática esteja presente.

Reconfigura-se o formato das políticas educacionais, que passam, além de atender aos interesses do empresariado, a assumir a agenda educacional colocada por organismos internacionais de diferentes matizes, com protagonismo do Banco Mundial. A partir disso, podemos destacar algumas características que nos ajudam a compreender as mudanças em curso, principalmente após o ano 2000, que influenciam a totalidade das políticas educacionais:

- O principal aspecto que passa a ser controlado, com aval das políticas educacionais, pelas forças dominantes e pela lógica empresarial diz respeito à gestão escolar. Nesse contexto, acompanha-se um considerável avanço do uso de mecanismos de gestão da informação dos resultados educacionais, o que se traduz em uma espécie de receituário de práticas a serem adotadas pelos gestores e professores. Como resultado, esses sistemas informatizados prometem elevação da qualidade da educação nas unidades escolares, isto é, aumento quantitativo dos índices de aprovação;

- Em geral, as políticas primam pela permanência dos estudantes nas escolas, o que exige uma série de ações que busquem complementar o tempo escolar com atividades no contraturno, ou seja, os estudantes permanecem na escola para realização de atividades de reforço escolar e outras oficinas, como é o caso do Programa Novo Mais Educação, que atualmente foi reformulado;

- Exige-se a ampliação dos recursos públicos para a educação, o que, em si, não chega a ser um problema. Entretanto, a elevação dos recursos, quando combinada com alterações curriculares que destituem os estudantes de conhecimentos elementares à formação humana e integral, acaba contribuindo para o treinamento de pessoas aptas a atender à lógica das relações sociais capitalistas sem problematizá-las. A transformação do FUNDEF em FUNDEB, ampliando-o para toda a educação básica, acaba por ser uma determinação do empresariado, e não encontrou resistência alguma no âmbito do governo e sociedade à época, ainda que tenha transcorrido na forma de um decreto;

- As mudanças orientam para a reestruturação curricular e avaliativa de todos os níveis educacionais, desde a educação infantil até o ensino superior. As principais mudanças no campo curricular ocorrem principalmente após 2006, justamente quando a ação organizada do empresariado se apresenta como “classe” (LEHER, 2014), um bloco histórico 
relativamente coeso, conforme a acepção gramsciana, pela disputa pelo direcionamento educacional. Na leitura da classe dominante, é fundamental determinar o tipo de conhecimento e conteúdo que a escola deve trabalhar, o que expressa claramente a forma de controle sobre o que será ensinado e como deve ser transmitido;

- A organização do empresariado, através do movimento "Todos pela Educação", reclama a reestruturação dos sistemas de ensino, o que perpassa pelo aumento no número de vagas em instituições públicas e privadas. Não é forçoso afirmar que todo o processo de ampliação do ensino técnico e superior, levado a cabo por REUNI e PROUNI, foi uma exigência colocada pelo empresariado, buscando atender à necessidade de formação de mão de obra competitiva e de sua ampliação, o que, em termos estruturais, reduz o seu valor no mercado de trabalho. Sob a retórica da democratização do acesso, ampliação do direito, a classe dominante vai cumprindo o seu papel e socializando seus interesses particulares;

- Entre as características que compõem a expressão do empresariado na direção das políticas educacionais em sua integralidade, contempla-se a participação da comunidade na escola. Este "comunitarismo" é formalizado através da interferência das organizações da sociedade civil no contexto escolar, voluntários da comunidade que oferecem oficinas no contraturno (ainda que a qualificação profissional não seja exigida) em troca de ajudas de custo. A presença da "comunidade" não é o problema. A contradição reside na crença de que os problemas da escola pública, que, a rigor, são carregados de elevada complexidade, podem ser resolvidos pela boa vontade daqueles que desejam ajudar, contribuindo para a difusão de um senso comum altamente perigoso de que qualquer pessoa pode interferir na construção dos caminhos educacionais.

- A centralidade do processo pedagógico escolar reside na aprendizagem dos estudantes, o que deve se traduzir na elevação dos índices quantitativos de aprovação e redução da evasão escolar. Mediante um complexo sistema de avaliações, as políticas educacionais no Brasil são conduzidas a atender o que é exigido nas provas e testes, aplicados desde as crianças até os jovens do ensino superior, não escapando a pós-graduação, ainda que esta última seja avaliada por uma agência específica - Capes.

Por isso, entendemos que vive-se no Brasil um período em que as políticas educativas, para atender aos interesses dominantes, incorporam, como estratégia de construção de manutenção de hegemonia, demandas históricas da classe trabalhadora, cujo 
objetivo é construir um consenso em torno do projeto de poder, no qual antagônicas posições sintam-se contempladas. Nas palavras de Coutinho (2008),

[...] os aparelhos burocráticos certamente recolhem as demandas populares de reforma, mas só as satisfazem após "selecioná-las" e "conciliá-las" com as demandas de outros setores e de torná-las assim compatíveis, em última instância, com os interesses de reprodução do capital (p. 41).

Cria-se a ilusão de que os direitos historicamente reivindicados serão atendidos e que as condições para superação dos problemas centrais que obstaculizam a educação serão criadas. Entretanto, a forma como essas "demandas" são operadas, desde a concepção no âmbito do Estado até a materialização prática, demonstra, sobretudo no Brasil, que essas políticas estão para além da simples concessão do Estado ou de conquistas de grupos sociais organizados em torno da garantia de direitos, mas articulam-se a um projeto fundado no consentimento, para o exercício do poder e da hegemonia do Capital sobre o Trabalho, passando a explicitar e exigir do Estado o seu caráter capitalista na forma mais explícita.

\section{CONSIDERAÇÕES}

Buscamos demonstrar que as alterações no plano do Estado, fruto da correlação de forças entre Trabalho e Capital é o que estruturalmente rege o funcionamento das políticas públicas educacionais. Entretanto, o que temos presenciado nas últimas décadas é uma acelerada ofensiva da classe dominante no controle das decisões educacionais, desde o que deve ser trabalhado em sala de aula, até o destino do financiamento público. Para nós, de acordo com os autores trazidos aqui, o crescimento deste controle sobre as políticas é expressão de uma crise sem resolução no plano conjuntural, que mostra os limites estruturais do próprio Capital (MESZAROS, 2009), seu metabolismo e sua incapacidade de autorreprodução, manifestando os obstáculos para superar as contradições por ele criadas.

De modo específico, a conformação da sociedade brasileira e a sua dependência econômica aos países ricos arquitetou um tipo peculiar de Estado marcado pela fragilidade patrimonialista e a promíscua relação entre o público e privado, de modo que o desenvolvimento das políticas educacionais tem sido orientado por uma disputa assimétrica e por vezes camuflada entre classes dominantes e os trabalhadores organizados. Infelizmente, nesta disputa, a maioria do povo que vive do trabalho tem sofrido perdas de difícil reversão, caso não haja uma resistência programática e radical, que não mais compactue em torno de 
uma agenda de consenso entre classes antagônicas, como ocorreu no último período, mas protagonize um passo a mais na constituição de lutas anticapitalistas, em que a educação pública seja exercida como um direito social elementar de fato e esteja voltada aos interesses dos trabalhadores, o que deve contemplar uma urgente transformação educacional.

\section{REFERÊNCIAS}

ANTUNES, Ricardo. Afinal, quem é a classe trabalhadora hoje? Estudos do Trabalho, Ano I, Número 1, Marília, Unesp, p. 01-09, 2008.

CARVALHO Elma Júlia Gonçalves de. Reestruturação produtiva, reforma administrativa do Estado e gestão da educação. Educação e Sociedade. Campinas, vol. 30, n. 109, p. 11391166, set./dez. 2009.

COUTINHO, Carlos Nelson. Contra a corrente. São Paulo: Cortez, 2008.

LEHER, Roberto. Atualidade da Política Pública Educacional e desafios da educação dos trabalhadores. In: PALUDO, Conceição (org.). Campo e Cidade em busca de caminhos comuns. Pelotas: UFPel, 2014, p. 159-178.

LEHER, Roberto. Um Novo Senhor da educação? A política educacional do Banco Mundial para a periferia do capitalismo. In: Revista Outubro. $3^{a}$ Ed. p. 19-30, 2012.

MESZAROS, István. Crise Estrutural do Capital. São Paulo: Boitempo, 2009.

PERONI Vera. Redefinições no papel do Estado: Parcerias público-privadas e a democratização da educação. Analíticos de Políticas Educativas, vol. 21, Janeiro, p. 1-14, 2013.

PERONI, Vera. Mudanças na configuração do Estado e sua influencia na política educacional. In: PERONI, Vera. BAZZO, Vera. Lucia. PEGORARO, Ludimar. (Org.) Dilemas da Educação Brasileira em Tempos de Globalização Neoliberal: entre o público e o privado. Porto Alegre: Editora UFRGS, 2006. p. 11-23.

SHIROMA, Eneida Oto EVANGELISTA Olinda. Estado, Capital e Educação: reflexões sobre hegemonia e redes de governança. Revista Educação e Fronteiras On-Line, Dourados/MS, v.4, n.11, p.21-38, mai./ago. 2014.

SHIROMA Eneida Oto. MORAES, Maria Célia M. de. EVANGELISTA, Olinda. Política educacional. Rio de Janeiro: DP\&A, 2002.

TORRES, Rosa Maria. Melhorar a qualidade da educação básica? As estratégias do Banco Mundial. In: TOMMASI, L. De; WARDE, J. M.; HADDAD, S. (Orgs.). O Banco Mundial e as políticas educacionais. São Paulo: Cortez Ed./Ação Educativa/PUC-SP, 2009. p. 125-194. 